\title{
Modeling the Biologically-Inspired Audio Storing Management Process (BiASMP) to Prevent Duplication of Digital Audio File in Personal Device
}

\author{
Hammuzamer Irwan bin Hamzah, Low Tan Jung, and Ariffin bin Abdul Mutalib
}

\begin{abstract}
This paper presents a method to prevent duplication of digital audio file in a personal device which is called biologically-inspired audio storing management process (BiASMP). This method is better than other software applications by preventing the duplication of digital music record from the start of the file being inserted into the personal device. Hence, the hard disk of personal device is always optimized with the required singular audio file. A comparative analysis is made to show advantage of BiASMP. The results of exemplar settings simulation are also provided to show how BiASMP works.
\end{abstract}

Index Terms-Biologically-inspired, software engineering, and multimedia database.

\section{INTRODUCTION}

Digital music records are stored as collection in personal device where the hard disk is shared with other multimedia files contents and their information (text, image, video, and etc.). The spaces become limited especially for the device with less storage capacity to the numerous records of multimedia files. The more files these personal devices store, the more possible it is for duplication of file to happen unnoticed [1]. Duplication of file should be removed rather than the replicates are kept, thus limiting the storage [2].

Music management software such as [3]-[9] do not prevent duplication of files from the beginning of the files being inserted. Here, the application tools detect the replicated files in the hard disk and move the duplicate files into a new created duplicate folder in the hard disk. Fig. 1. shows a model to represent this situation. It is up to the user then whether to delete those file hence it makes the hard disk of the personal device optimized from duplicated files of digital music records.

iTunes [10] also provides management of music files by detecting the duplicated files and move them into duplication folder. Besides that, iTunes also automatically organize the music collection by sorting the single audio files into iTunes folder. However, users still need to delete the duplicated files in the duplication folder to make the storage of personal device optimized and free of duplicated files, also the records in the hard disk which are taken from the hard disk and

Manuscript received June 18, 2013; revised September 16, 2013.

Hammuzamer Irwan bin Hamzah and Ariffin bin Abdul Mutalib are with the School of Multimedia Technology and Communication, Universiti Utara Malaysia (e-mail: hammuzamer@yahoo.com).

Low Tan Jung is with Computer and Information Sciences Department, Universiti Teknologi PETRONAS, Perak, Malaysia. inserted into iTunes folder, they are not automatically deleted. Fig. 2. shows the iTunes duplication detection model.

Based on the scenarios in Fig. 1 and Fig. 2, duplication of digital audio files so far occur in the hard disk of personal device. The music collection is not optimized until the music management software. However, the detected duplicated files still exist because they are just moved into another folder.

There should be a well-managed process to recognize and learn any inserted music record. There should also be a mechanism that provide assistant to organize the storage of a personal device. Therefore, a management process to prevent duplication from happening since the file being inserted into personal device is required.

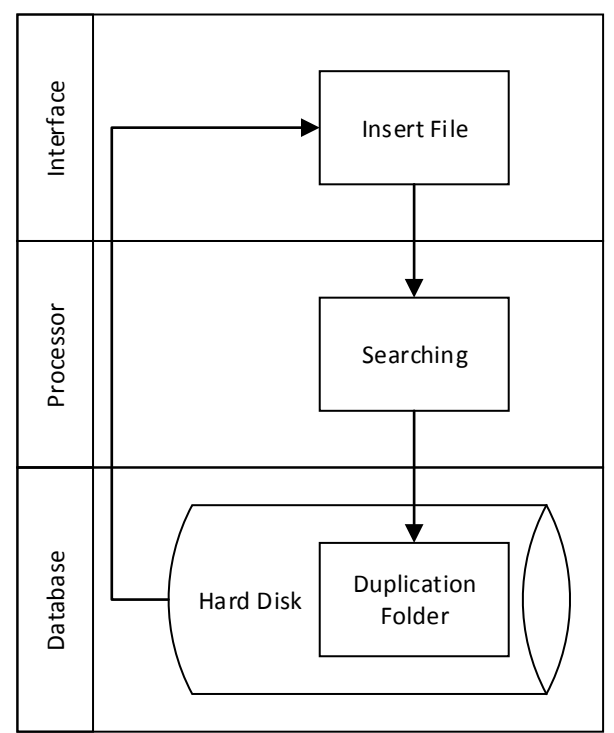

Fig. 1. Other duplication detection software model.

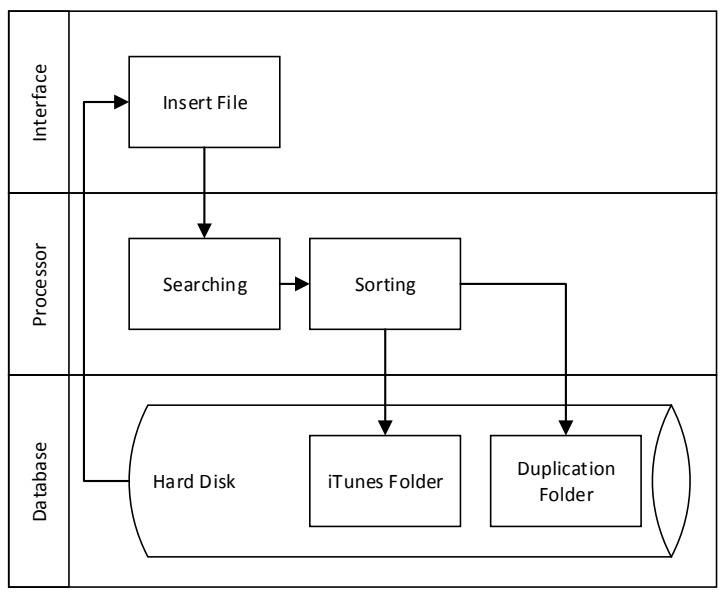

Fig. 2. iTunes duplication prevention model. 


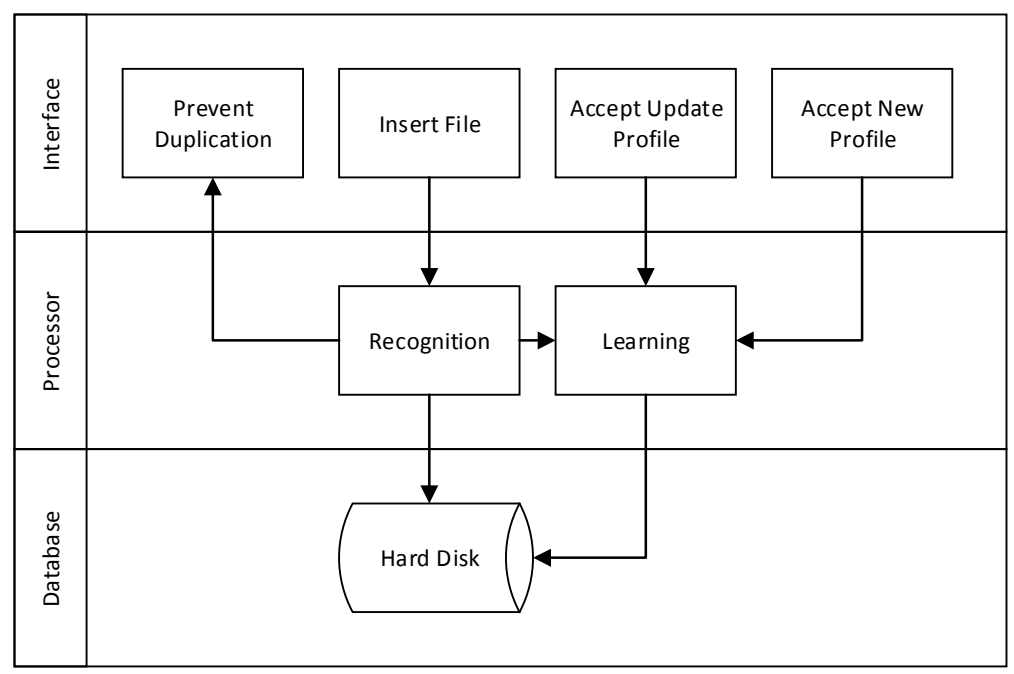

Fig. 3. BiASMP.

Biologically-Inspired Audio Storing Management Process (BiASMP)

Sound is one of the media that brings information to human. Human capable to recognize certain sound. Human also capable to learn a new sound. What makes more impressive is human capable to memorize and recall the sound. All of these capabilities are from the biologically-inspired concept especially towards the human learning perspective. It is a natural behavior for a human to recognize any sound that is memorized in the brain. Furthermore, whenever there is a new sound heard, the brain tries to learn for new information of that particular sound. However, not all learned information can be knowledgeable. It is through truth and belief where information becomes knowledge to human 1 . New knowledge can be obtained through new learning. In other words, it is through cognitive learning 2 and constructive learning 3,4 which supply valuable knowledge for human to remember. Here, human can judge right or wrong and decide the correct information to remember. The brain stores much useful knowledge. At any time human can recall the memories and match with the listened sound.

Biologically-inspired audio storing management process or BiASMP can prevent duplication of digital audio files in personal device from occurring from the start of the file being inserted. It provides recognition and learning function to assist user for adding files which only not in their hard disk yet. It adapts human biologically-inspired concept for preventing duplication from happening [11]. Fig. 3. shows how BiASMP works. This study analyzes and identifies the elements for the requirements of BiASMP. BiASMP adapts the human ear [12] as the interface to accept and configure the inserted file and send it the matching process. The human brain [13] is adapted as the processor for the matching process and as the memory [14] for the storage. Beside the brain and memory process, for the matching procedure, this study introduces the cognitive [15] and constructive [16]

\footnotetext{
${ }^{1}$ http://dictionary.reference.com/browse/knowledge

${ }^{2} \mathrm{http}$ ://ezinearticles.com/?Definition-of-Cognitive-Learning\&id=365039

${ }^{3} \mathrm{http} / / / \mathrm{www}$. exploratorium.edu/IFI/resources/constructivistlearning.html

http://www.ndt-ed.org/TeachingResources/ClassroomTips/Constructivist $\%$ 20_Learning.htm
}

learning functions supporting the recognition function for giving assistance to user to store only the desired file. Other than the biologically-inspired elements, there are several elements of digital audio concept adapted for the development of BiASMP based on the requirements and issues suggested by [17] and [18]. The explanation of the elements of BiASMP is described more in detail by [11]. Based on Fig. 3., to support the recognition and learning process, a matching condition is made for the prevention action and control action for assisting user to add a digital music record into their personal device. This matching classification is entitled as CCL matching condition (See Fig. 4. in next page). The full descriptions of how BiASMP executes are explained in detail in the simulations and exemplar settings section. To further describe how BiASMP executes the CCL function, an algorithm is formulated such as below:

\section{START}

INSERT file;

IF checkAudioCompatibility THEN

EXECUTE ccl;

IF similarMatch THEN

DO recognition;

IF acceptListedRecord THEN

DO duplicatePreventionAction;

ELSE partialMatch;

ENDIF;

ELSEIF partialMatch THEN

DO cognitiveLearning;

IF acceptNewUpdatedProfile THEN

UPDATE memory;

EXECUTE ccl;

ELSE noMatchingAtAll;

ENDIF;

ELSEIF noMatchingAtAll THEN

DO constructiveLearning;

IF acceptNewProfile THEN

UPDATE memory;

ELSE cclFailed;

ENDIF;

ELSE cclFailed;

ENDIF; 
ENDIF;

END;

\section{COMPARATIVE ANALYSIS}

The music management software [3]-[9] are compared with BiASMP (X). A list of features to prevent duplication of digital audio files in personal device has been identified. The empirical analysis has been done and the results are shown in Table I. The left side column is the identified features, and the other columns are tools and their capabilities.

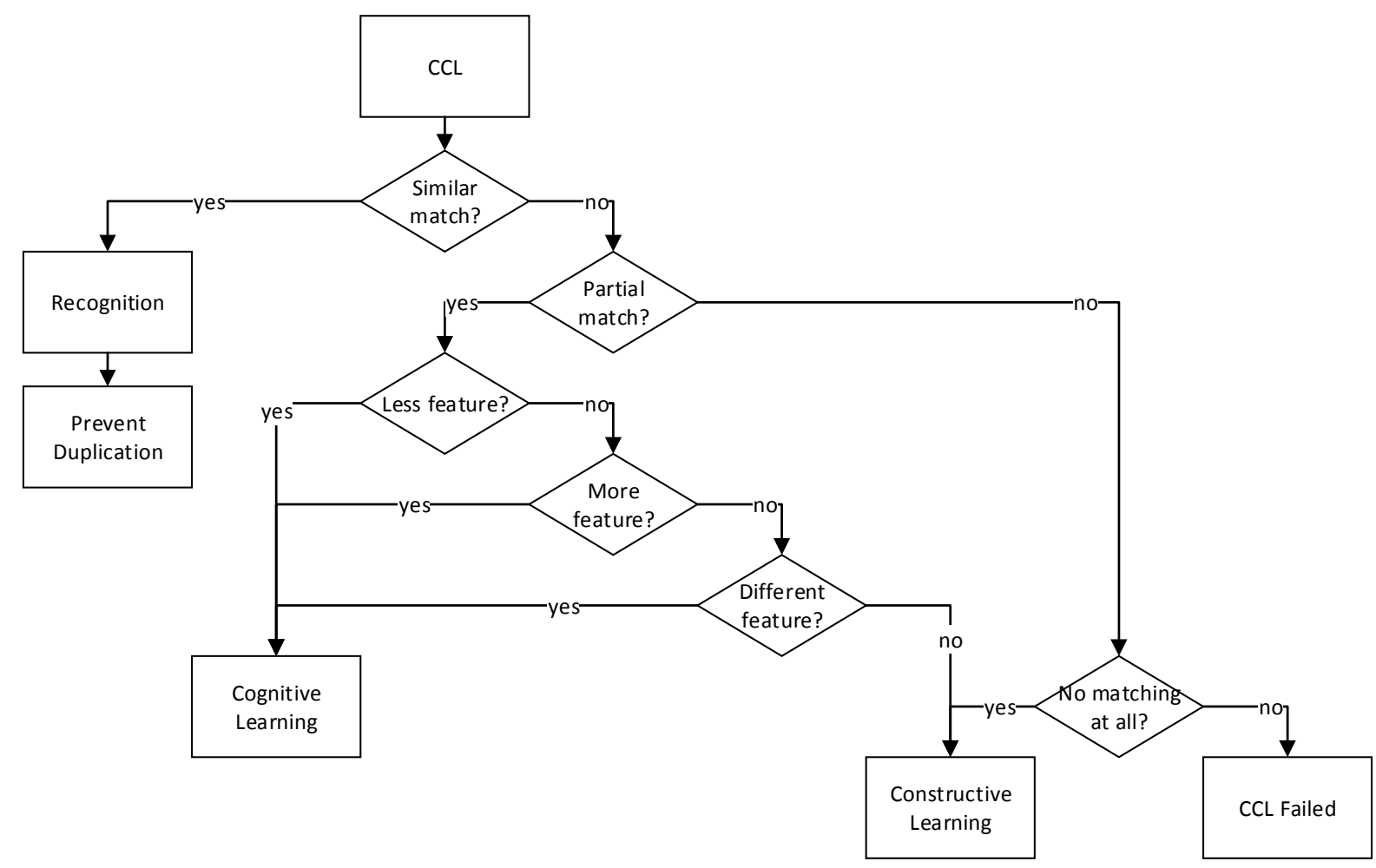

Fig. 4. CCL matching condition.

TABLE I: COMPARATIVE ANALYSIS

\begin{tabular}{|c|c|c|c|c|c|c|c|c|}
\hline Features & {$[3]$} & [4] & {$[5]$} & {$[6]$} & [7] & [8] & [9] & $(\mathrm{X})$ \\
\hline Detect duplicate file & I & 1 & / & I & I & I & I & I \\
\hline Clean duplicate file & - & - & - & - & - & - & - & l \\
\hline Recognize file before inserted & - & - & - & - & - & - & - & l \\
\hline Search storage for similar file before inserting file & - & - & - & - & - & - & - & l \\
\hline Filter file before stored into personal device & - & - & - & - & - & - & - & l \\
\hline Implement multimedia data modeling & - & - & - & - & - & - & - & l \\
\hline Implement MPEG-7 DSs & - & - & - & - & - & - & - & l \\
\hline Implement DRM & - & - & - & - & - & - & - & l \\
\hline Implement audio watermarking & - & - & - & - & - & - & - & l \\
\hline Implement audio fingerprinting & l & l & l & l & / & / & l & l \\
\hline Implement content based retrieval & / & l & / & l & / & / & / & l \\
\hline Implement semantic based retrieval & l & l & l & l & / & I & l & l \\
\hline Implement audio classification & - & - & - & - & - & I & - & l \\
\hline Implement audio object recognition & l & l & l & I & I & l & / & I \\
\hline
\end{tabular}

II.

\section{Simulations OF EXEMPlar SETtingS}

Exemplar settings exhibit the simulations executed to show the recognition, cognitive learning, and constructive learning functions.

TABLE II: INITIAL RECORD IN MEMORYTABLE.

\begin{tabular}{llll}
\hline \hline Rec. & Song & Artist & Album \\
\hline- & - & - & - \\
\hline \hline
\end{tabular}

\section{A. Constructive Learning - Null Record}

This simulation starts with an empty storage. The initial State of the memory able is planned as described in Table
The memory Table is currently empty. For the first example, the simulation requests the user to add new file. The procedures for this example are executed as in the Example 1.

\section{Example 1: Adding File}

SET environment inputFile $=$ Selamat Tinggal Akhirnya.mp3

memoryTable $=$ null

EXECUTE ccl

ACCEPT newProfile

DO constructiveLearning

UPDATE memoryTable $=\{$ Selamat Tinggal 
Akhirnya.mp3

After adding the new file into the memoryTable, the first record is as shown in Table III.

TABLE III: CONSTRUCTIVE LEARNING IN MEMORY TABLE

\begin{tabular}{llll}
\hline \hline Rec & Song & Artist & Album \\
. & & & \\
\hline 1. & Selamat Tinggal Akhirnya.mp3 & Aizat & Percubaan Pertama \\
\hline \hline
\end{tabular}

Example 1 exhibits the constructive learning function. The next example shows the recognition function.

\section{B. Recognition - Similar Object}

The simulation for the example of recognition function only can be performed after the memoryTable is not null. From the Example 1 in the previous section, the record in the memory Table enables the recognition function to be performed. To match the record, the setting for the procedures in Example 2 is planned as below.

\section{Example 2: Matching Same Record \\ SET environment inputFile $=$ Selamat Tinggal Akhirnya.mp3 memoryTable $=\{$ Selamat Tinggal Akhirnya.mp 3$\}$ EXECUTE ccl \\ ACCEPT listedRecord \\ DO recognition \\ DO duplicatatePreventionAction}

From this example, a perfect match occurs due to the same files are matched. BiASMP executes recognition function. BiASMP executes prevention action. User is assisted not to store the same file into the personal device.

\section{Cognitive Learning - Similarity in Object Features}

Example 3 is to show the cognitive learning function of adding new file with some similar object features. This example setting is with the same artist and the same album, but the song is different. The procedures are planned as below.

\section{Example 3: Adding New File - Cognitive Learning (i) SET environment inputFile $=$ Cintai Diriku.mp3 \\ memoryTable $=\{$ Selamat Tinggal Akhirnya.mp 3$\}$ \\ EXECUTE ccl \\ ACCEPT updateProfile \\ DO cognitiveLearning \\ UPDATE memoryTable $=\{$ Cintai Diriku.mp 3$\}$}

After adding the new the file into the memoryTable, the records increase. This can be seen in Table IV.

TABLE IV: COGNITIVE LEARNING IN MEMORYTABLE - SIMILAR OBJECT (I)

\begin{tabular}{llll}
\hline \hline Rec & Song & Artist & Album \\
. & & & \\
\hline 1. & Selamat Tinggal Akhirnya.mp3 & Aizat & Percubaan Pertama \\
2. & Cintai Diriku.mp3 & Aizat & Percubaan Pertama \\
\hline \hline
\end{tabular}

Example 4 shows another example for cognitive learning function to adding new file with another some similar object features. This time the same artist is used but with different album. The settings are planned as below.
Example 4: Adding New File - Cognitive Learning (ii) SET environment,

inputFile $=$ I Go.mp3

memoryTable $=\{$ Selamat Tinggal Akhirnya.mp3, Cintai Diriku.mp3

EXECUTE ccl

ACCEPT updateProfile

DO cognitiveLearning

UPDATE memoryTable $=\{$ I Go.mp $\}$

After adding the new file using different setting of the same artist but with the different album, it increases the record in the memory Table. Table $\mathrm{V}$ shows the current records in the memory Table.

TABLE V: Cognitive LEARNING IN History MEMory - Similar OBJECT (II)

\begin{tabular}{llll}
\hline \hline Rec & Song & Artist & Album \\
. & & & \\
\hline 1. & Selamat Tinggal Akhirnya.mp3 & Aizat & Percubaan Pertama \\
2. & Cintai Diriku.mp3 & Aizat & Percubaan Pertama \\
3. & I Go.mp3 & Aizat & OST Talent Time \\
\hline \hline
\end{tabular}

There is another example to show that BiASMP capable to organize audio storage with totally different object. The example is shown in the following section.

\section{Constructive Learning - New Object Features}

Example 5 is to exhibit the constructive learning function of a totally different object. The procedures for the example are planned as below.

\section{Example 5: Adding New File}

SET environment, inputFile $=$ Faizal Tahir - Hanyut (Akustik).mp3

memoryTable $=\{$ Selamat Tinggal Akhirnya.mp3, Cintai

Diriku.mp3, I Go.mp3\}

EXECUTE ccl

ACCEPT newProfile

DO constructiveLearning

UPDATE memoryTable $=\{$ Faizal Tahir - Hanyut (Akustik).mp3\}

Example 5 is actually the same setting as Example 1. However, Example 1 is initiated with empty record in the memoryTable. Whereas, Example 5 exhibits the constructive learning function with the records of memory Table not empty. Therefore, Table VI shows the newly added record is listed in the memory Table.

TABLE VI: CONSTRUCTIVE LEARNING IN MEMORY TABLE

\begin{tabular}{llll}
\hline \hline Rec. & Song & Artist & Album \\
\hline 1. & Selamat Tinggal & Aizat & $\begin{array}{l}\text { Percubaan } \\
\text { Pkhirnya.mp3 }\end{array}$ \\
& Aertama \\
2. & Cintai Diriku.mp3 & Aizat & $\begin{array}{l}\text { Percubaan } \\
\text { Pertama }\end{array}$ \\
3. & I Go.mp3 & Aizat & OST Talent Time \\
4. & Faizal Tahir - Hanyut & Faizal & Adrenalin \\
& (Akustik).mp3 & Tahir & \\
\hline \hline
\end{tabular}

\section{CONCLUSION}

With all the examples exhibited above, it describes the 
recognition function, the cognitive learning function, and the constructive learning function. This proves that BiASMP can prevent duplication of digital audio file in personal device.

\section{REFERENCES}

[1] K. Kusama and T. Itoh, "Mus Cat: a music browser featuring abstract pictures and zooming user interface," in Proc. the 2011 ACM Symposium on Applied Computing, pp. 1222-1228, 2011.

[2] D. Bitton and D. J. Dewltt, "Duplicate record elimination in large Data files," Computer Programming and Software, vol. 8, no. 2, pp. 255-265, 1983.

[3] Abee Mp3 Duplicates Finder. (2008). [Online]. Available: http://www. Abeetech.Com/Mp3-Duplicates-Finder/

[4] Dupeguru Music Edition. (2012). Hardcoded Software. [Online] Available: http://www.Hardcoded.Net/Dupeguru_Me/

[5] Duplicate Cleaner - Find Duplicate Files. (2012). [Online]. Available: http://www. Digitalvolcano.Co.Uk/Content/Duplicate-Cleaner

[6] Duplicate Music Files Finder. (2008). [Online]. Available: http://www.Lcibrossolutions.Com/Dmff

[7] Musicbee - Music Manager and Player. (2012). [Online]. Available: http://www. Getmusicbee.Com/

[8] Similarity. (2013). GAR Software. [Online]. Available: http://www. Similarityapp.Com/

[9] Tuneup. (2012). Tuneup Media. [Online]. Available: http://www.Tuneupmedia.Com/

[10] Archived - Itunes 8: Finding And Removing Duplicate Items. (2013). [Online]. Available: http://www. Support.Apple.Com/Kb/Ht1417

[11] H. I. Hamzah and L. T. Jung, "Implementing bism and CCL algorithm for managing audio storage," in Proc Knowledge Management International Conference. pp. 1-8, 2012.

[12] T. Reynolds, "Ear, nose and throat problems in accident and emergency," Nursing Standard, vol. 18, no. 26, pp. 47-53, 2004.

[13] M. W. Dubin. How The Brain Works. [Online]. Available: http://www.howourbrainswork.com/.

[14] L. R. Squire, "Memory Systems of the brain: a brief history and current perspective," Neurobiology of Learning and Memory, vol. 82, no. 3, pp. 171-177, 2004.

[15] K. H. Pribram, "The cognitive revolution and mind/brain issues," The American Psychologist, vol. 41, no. 5, pp. 507-520, 1986.

[16] R. Parekh, J. Yang, and V. Honavar, "Constructive neural-network learning algorithms for pattern classification," IEEE Transactions On Neural Networks / A Publication of The IEEE Neural Networks Council, vol. 11, no. 2, pp. 436-451, 2000.

[17] D. A. Adjeroh and K. C. Nwosu, "Multimedia database management-requirements and issues," IEEE International Conference On Multimedia, vol. 4, no. 3, pp. 24-33, 2007.

[18] W. I. Grosky, "Managing multimedia information in database systems," Communications of the ACM, vol. 40, no. 12, pp. 72-80, 2001. 4.

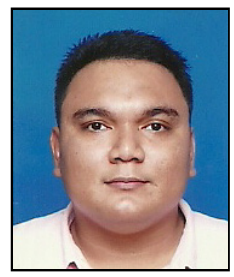

Hammuzamer Irwan bin Hamzah studied for bachelor of information technology with honors majoring in software engineering at Universiti Utara Malaysia, Kedah, Malaysia. He then obtained his $\mathrm{MSc}$ in real-time software engineering at centre for advanced software engineering (CASE), UTMKL, Kuala Lumpur, Malaysia. He is currently pursuing his $\mathrm{PhD}$ at Universiti Teknologi PETRONAS, Perak, Malaysia. He is now working as Tutor at School of Multimedia Technology and Communication, Universiti Utara Malaysia teaching undergraduate students for more than five years. He teaches courses such as real-time programming, www programming, multimedia database, multimedia networking, software engineering, integrative media, ergonomic, ubiquitous technology, and some more courses.

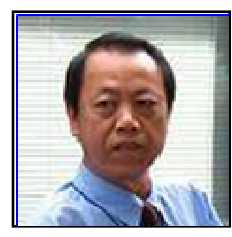

Low Tan Jung obtained his bachelor degree in computer technology from Teesside University, UK in 1989 and MSc IT from National University of Malaysia in 2001. He achieved his PhD research in Universiti Teknologi PETRONAS in Underwater Acoustic Communications. He is currently a senior lecturer in computer and information sciences Department, Universiti Teknologi PETRONAS, Perak, Malaysia. He joined UTP in late 2003. Some systems he has developed are like remote monitoring and alerting system for oil pipelines corrosion detection using SMS via GSM network, 3D Spatial Points Detector - using 2 webcams to detect 3D points, an SMS based Q\&A system for large conference hall, Sign-to-voice and Voice-to-sign language translator for speech impaired people, Wireless Sensor Network for Water Resource Monitoring \& Management, and Wireless sensor Network System for Green IT. Low is currently involved in R\&D for extending the Green IT project into green data center applications and dynamic PCs power management to provide solution for $\mathrm{CO} 2$ emission reduction. Low has been in the academic line for more than two decades already mainly as lecturer cum researcher in various public and private institutes of higher learning. He teaches various engineering and ICT courses. His research interests include wireless technology, embedded systems, wireless sensor network, and grid computing.

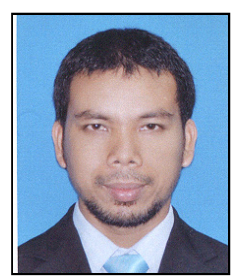

Ariffin bin Abdul Mutalib and gained his $\mathrm{PhD}$ in Information Technology from Universiti Utara Malaysia in 2009. His has Msc. in interactive multimedia from Heriot-Watt University, Scotland, UK in the year 2001. He obtained his bachelor in information technology from Universiti Utara Malaysia in 1999 . He is currently a senior lecturer at the School of multimedia technology and communication, Universiti Utara Malaysia. He is also the vice director at the Institute of Quality Management, Universiti Utara Malaysia. His expertise is in HCI, User Experience, Usability, eLearning, Web-based application, Emerging Technologies and many more. He teaches courses for undergraduate such as Multimedia Networking, Digital Audio Technology, User-Centered Design, WWW Programming, Ubiquitous and Wearable Computing, Multimedia Seminar, Human-Computer Interaction, and Integrative Media. He also teaches for Graduate student courses such as Information Technology For Managers, Usability Engineering, Research Methodologies, and Information System Management. 